\title{
INDIRECTNESS, INEXPLICITNESS AND VAGUENESS MADE CLEARER ${ }^{1}$
}

\author{
Winnie Cheng and Martin Warren
}

\begin{abstract}
The ability to do indirectness, inexplicitness and vagueness is a key component in the repertoire of all competent discoursers and these are commonplace phenomena in written and spoken discourses, particularly in conversations. The study reported in the paper seeks to delineate and exemplify these three terms which are used frequently in the literature, but which are potentially confusing as they are not always unambiguously defined and consistently applied. The purpose of the study is to describe the differences between the three terms in terms of their pragmatic usage and functions, drawing upon a corpus of naturally-occurring conversational data between Hong Kong Chinese and native speakers of English. In so doing, this study underlines the widespread occurrence of these forms of language use and the ways in which participants in spoken discourse employ them to jointly construct both context and meaning.
\end{abstract}

Keywords: Indirectness, Inexplicitness, Vagueness, Hong Kong Corpus of Spoken English, English conversations.

\section{Introduction}

This paper begins by acknowledging a fact: All language in use is context-dependent. In conversation, for instance, the full context within which it takes place is neither fixed nor fully shared by the participants; the context is jointly constructed through and by the language. Consequently, participants in a conversation do not necessarily share things as they might think they do. The external context alters with each utterance and is essentially different for each participant so that while conversation is a shared experience, each participant's experience is unique and thus interpretations may differ. Therefore any part of an utterance, which relies on an assumed shared context that is not actually shared with the hearer, requires that the hearer creates a context based on language. This is different from the general belief that the hearer uses the context to interpret what is said. In this way, aspects of context are gradually built up by taking what is assumed to be shared between the participants. Since the external context is not fixed, shared knowledge is constantly being constructed and is not some kind of unsubstantiated library to which conversational participants have full and equal access. Language in use can never fully represent a

\footnotetext{
${ }^{1}$ The work described in this paper was substantially supported by grants from the Research Grants Council of the Hong Kong Special Administrative Region (Project Nos. G-S357 and B-Q396).
} 
speaker's meaning and, in this broad sense, all language in use is ultimately contextdependent.

The present study examines conversations which have integrated the immediate context, in the sense of locally organized and jointly constructed linguistic interaction, and the wider context, in the sense of potential socio-cultural contextual influences on linguistic choices. This study examines three forms of language use which are heavily contextdependent and which also serve as archetypal examples of the ways in which language creates context rather than simply reflects it. These forms are categorized under three major headings: Indirectness, inexplicitness and vagueness.

\section{Rationale for the study}

The study aims to offer delineations of indirectness, inexplicitness and vagueness in terms of their actual realizations. The reason for this is that these terms have been used by others in the past, but they have neither been clearly defined nor consistently applied with the result that there is no generally accepted understanding as to what these terms mean or what manifestations they either include or exclude. An overview of the literature has produced a variety of definitions and/or realizations invoked by others when employing these three terms and related terms that describe similar phenomena. In addition to contributing to the general field of pragmatics, this study might benefit those involved in teaching English language to learners of English as a second or foreign language. The need for learners of English to be competent in processing these phenomena is often overlooked by practitioners.

\section{Definitions of indirectness, inexplicitness and vagueness}

Not only the ways in which the terms indirectness, inexplicitness and vagueness are defined but also the terms with which indirectness, inexplicitness and vagueness are juxtaposed can vary from one writer to another. To begin with, 'indirectness' is perceived as the converse of being 'explicit' or 'straightforward' (Sew 1997:363) or 'being outwardly vocal or blunt' in verbal context (Sew 1997: 358). Similarly, Placencia (1995) contrasts 'indirectness' with 'explicitness', rather than with 'directness'. The realizations of indirectness can vary too, and these include pragmatic forms of politeness (McCarthy 1998); 'speech acts of indeterminate illocutionary points', which has an inherent pragmatic role (Sew 1997: 358); and ellipsis, abbreviations and ambiguity (Placencia 1995). Goatly (1995) suggests that indirectness realized in speech acts, such as a directive in the classroom context, requires inferencing by the hearer and helps to develop the pragmatic competence of the hearer. Stenström (1994: 114-115), discusses 'implying' as a responding strategy in spoken discourse. So the response 'not many', termed an 'imply' strategy, to the question 'do you want people to come to the registry office' answers the question indirectly and requires the hearer to infer the direct answer from it, whereas a response such as 'yes I do but not too many' answers the question directly.

The second term 'inexplicitness' is defined, for instance, by Dines (1980: 20) as instances, which she calls 'dysfunctional units', where speakers 'misjudge' the extent of 
the shared assumptions, and dysfunctional units 'would be marked by request for clarification'. In other words, Dines seems to use the term 'inexplicitness' to describe instances of pragmatic failure. Biber (1988: 143), on the other hand, uses the terms 'explicit' and 'situation-dependent' to describe a scale used to compare discourse types, 'explicit' being references that can be understood with access to the situation in which they occur. Conversely, a discourse becomes inexplicit, presumably, when references can not be understood by accessing the immediate context (Biber 1988). The term 'heavily context-dependent words', such as that, here, there, he and it, is used by Carter and McCarthy (1994: 67-68) to describe words which require an understanding of the 'entities and locations in the immediate environment'.

Explicitness is traditionally juxtaposed with implicitness; their distinction lies between what is encoded in an utterance (explicit) and what is inferrable from an utterance (implicit) (Bertuccelli Papi 1997: 23). This traditional view of the distinction between explicitness and implicitness is, however, rejected by Sperber and Wilson (1986), who conceive 'inexplicitness' as both classificatory and comparative. 'Explicitness' is defined in this way: 'An assumption communicated by an utterance $U$ is explicit if and only if it is a development of a logical form encoded by $U$ ' (Sperber and Wilson 1986: 182). An assumption which is explicitly communicated is called an 'explicature' which is 'a combination of linguistically encoded and contextually inferred conceptual features. The smaller the relative contribution of the contextual features, the more explicit the explicature will be, and inversely' (Sperber and Wilson 1986: 182). Bertucelli Papi (1997: 23) points out that if this is the case, the "crucial question to answer then becomes: What are the limits of explicitness, up to what degree of explicitness are we authorized to develop a logical form, and what exactly are the boundaries which separate explicatures from implicatures?'

Two terms which are often used interchangeably by writers with 'inexplicitness' are 'implicitness' and 'implied meaning' and, again, these are terms which are sometimes used to describe very different phenomena and their linguistic realizations. So for Bertuccelli Papi (1997: 20), implicitness phenomena are dealt with under 'entailments, presuppositions, sous-entendus, implicatures, explicatures and implicitures' which makes for a very broad use of the term. For Riley (1988: 94) and Stenström (1994: 114-115), 'implied meaning' is used in juxtaposition with 'explicit meaning' in the sense of conversational implicature ('implied meaning') versus stated meaning ('explicit meaning'). Others focus on lexical and grammatical features, for instance, Mazzie (1987: 31) distinguishes between 'implicit forms' of language use, such as ellipsis, deixis and personal pronouns, and 'explicit forms' of language use, such as complete sentences and full noun phrases. Jucker and Smith (1996: 5) list the 'implicit strategies' available to speakers in conversations which include personal pronouns, similar to that listed by Mazzie (1987), but Jucker and Smith differ from Mazzie by including definite noun phrases and tag questions.

Bach (1994: 124-125) proposes the term 'impliciture' to account for the fact that 'linguistic meaning underdetermines speaker meaning because of the need for disambiguation and reference assignment, and because people can speak figuratively or indirectly'. Bach's notion of impliciture is 'to distinguish not only the implied from the explicit but the implicit from the implied', and Bach sees Grice's notion of implicature doing only the former, i.e. distinguishing the implied from the explicit. Bach (1994) claims that utterances are 'semantically underdeterminate' and require the hearer to 'complete' (completion) or 'expand' (expansion) on what is implicit, and such utterances illustrate that 
a speaker can, even without using any ambiguous or indexical expressions and without speaking figuratively or indirectly, mean something without making it explicit (Bach 1994: 125).

The third form of language use, 'vagueness' (Kempson 1977), is also used differently in the literature. Vagueness has been interpreted by different scholars as 'fuzziness, vagueness, generality, ambiguity and even ambivalence' (He 2000: 7). There are some in the field who make reference to 'vague language' (Channel 1994) and 'vague expressions' (Carter and McCarthy 1997) while others talk of 'imprecision' or 'imprecise language use' (see for example, Crystal and Davy 1975: 112-114; Dubois 1987). Stubbs (1996: 202) places 'vagueness and lack of commitment' in opposition with 'certainty and commitment', and so 'vagueness' is equated with uncertainty. Interestingly, while terminology differs, the realizations of vagueness are more consistent across the various studies. Crystal and Davy (1975: 112-114) identify types of lexical vagueness, which are a mixture of 'precision and imprecision', on a spectrum from items which express 'total vagueness' like thing, whatsit and so on, to examples such as I've got some tomatoes, beans and things, and the use of the suffix -ish in colloquial English. Dubois (1987: 531) describes the use of hedges such as close to, about, around, on the order of, something like and so forth with numbers in biomedical slide talks as 'imprecise' numerical expressions. Speakers and writers employ these expressions to express uncertainty in relation to one's own or somebody else's findings and to 'diminish precision'. Wierzbicka (1986: 597) adopts what she terms a 'radically semantic' approach rather than a 'radically pragmatic approach' to what she calls 'approximatives' and she looks at just, at least, only, merely and at the most. She argues that all expressions have meanings that are recoverable and thus have 'rigorous semantic explications' (1986: 597). She concludes that she has shown that "even 'vague', 'subjective' and 'fuzzy' words such as particles in general and 'approximatives' in particular, do have a meaning, and that this meaning can be stated". However, it is clear from her attempts to pin down the meanings of approximatives that they do not have one identifiable meaning. For example, she lists the meanings of at least as follows:
"it is not less than $\mathrm{X}$
it could be a little more than that
one could think that it would be less than that"

(Wierzbicka 1986: 598)

Wierzbicka's attempts to assign a range of meanings to approximatives such as at least confirm that they are inherently vague. If one says 'there were at least fifty people at the meeting', the actual number of people at the meeting remains vague as a result of using an approximative - the hearer cannot assign a precise number to 'at least fifty people'.

The above illustrates that the consistent use of these terms are problematic on several levels, namely definitions of the terms, what constitutes the opposites of these terms and then the definitions of those opposites. In the following sections there follows an attempt to delineate, as far as possible, the notions of indirectness, inexplicitness and vagueness and their realisations, based on a review of the literature. In this study these concepts and the forms by which they are realised are conceived of in terms of the following dichotomous relationships: Directness vs. indirectness, explicitness vs. 
inexplicitness, and precision vs. vagueness.

\section{Analysis of data}

The data examined in the present study were taken from a corpus of naturally-occurring intercultural English conversations collected and compiled in Hong Kong. This corpus, the Hong Kong Corpus of Spoken English (HKCSE), is made up of four sub-corpora, one of which comprises conversations (see Cheng and Warren 1999a) between native speakers of English and Hong Kong Chinese (i.e. native speakers of Cantonese). The importance of examining intercultural communication has been acknowledged as much of the English now spoken around the world involves at least one non-native speaker (see, for example, Graddol and Meinhof 1999; Labrie and Quell 1997). While the data are clearly intercultural in nature, this study is not concerned with exploring the cultural dimensions of the forms of indirect, inexplicit and vague language use. This is not to say that the use of particular forms, and their particular manifestations, is not in part influenced by individual speakers' cultural backgrounds. Here, it is suggested that the descriptions hold, in English at least, regardless of the participants' first language, cultural background, or the culture in which they are operating.

In addition to delineating the notions of indirectness, inexplicitness and vagueness, the present study illustrates the ways in which these categories are realized in the discourse, and thus showing how pragmatic meanings are inextricably linked to lexico-grammatical choices made moment by moment by the speaker. This study, therefore, falls within the tradition of studies of English that argue it is possible to encode interpersonal, pragmatic meanings in lexico-grammatical choices made by the speaker (or writer) (see for example, Stubbs 1996: 196-229). This approach has been adopted by a wide range of researchers examining such connections through, for example, studies of noun morphology (see, for example, Levinson 1983: 8-9), connectors (see, for example, van Dijk 1979), hedging through modal verbs (see, for example, Brown and Levinson 1987) and other verbal forms (see, for example, Hunston 2002).

Extract 1, which is taken from a conversation between two friends who are discussing speaker A's recent wedding, presents an introduction to each of the three forms.

\section{Extract 1}

\section{B: male British}

\section{a: female Hong Kong Chinese}

1 B: $\quad$ we did the er didn't do the actual wedding here but we did have a banquet

2 a: the banquet

3 B: in a hotel and then I have to go and claim my bride by performing challenges

4 a: $\quad$ yes

5 B: by singing $\underline{\underline{\text { things }}}$

6 a: $\quad(($ laugh $))$

7 B: it's embarrassing

8 a: $\quad$ really a clown ((laugh))

9 B: $\quad$ clown yes kind of my friend is like er I delegate to him to delegate to some 


$\begin{array}{lll} & & \text { of } \\ 10 & & \text { my friends it's good fun good fun yea yea very good } \\ 11 & \text { a: } & ((\text { laugh })) \\ 12 & \text { B: } & \text { so (.) I suppose er kids will be our next (.) achievement } \\ 13 & \text { a: } & \text { yea }\end{array}$

The partial analysis begins on line 5 with an example of vague language use (shown double underlined) when speaker B says things. This is an example of a speaker employing vagueness by choice of a vague word or phrase (Channell 1994: 18). Three more examples of vagueness are found on lines 9-10. First, speaker B uses a vague additive (Channell 1994: 18), kind of, which adds vagueness to his otherwise non-vague clown. Second, B twice employs vagueness by scalar implicature, some and very, on lines 9 and 10 . Such items are inherently vague and need to be interpreted in relation to a range or scale of terms that are ranked relative to one another in meaning and, in turn, there needs to be a shared understanding of this ranking among the discourse participants. On line 7, speaker B's use of $i t$ is an example of anaphoric reference and belongs to the category of inexplicitness (shown in italics) (Cheng and Warren 1999b: 298-299). The term 'reference' here is used to cover items which are not "interpreted semantically in their own right" but which "make reference to something else for their interpretation" (Halliday and Hasan 1976: 31). Another form of inexplicitness is found on lines 8 and 9 when speakers B and a use ellipsis (Cheng and Warren 1999b: 296-298), [you are] really a clown and [a] clown, to reduce their utterances by choosing to leave certain elements unsaid (a hypothetical understanding of what the speakers left unsaid has been put in brackets, the status of which will be discussed later in the paper). The use of deixis by speaker B on lines 9-10 by means of the pronouns, my, I and him, is also a form of inexplicitness (Cheng and Warren 1999b: 298299). On line 12, there is an example of indirectness (shown underlined) when B says $I$ suppose er kids will be our next (.) achievement. This is an example of a conversational implicature (Grice 1975) whereby speaker B implies that he and his wife are planning to start a family and speaker a must infer B's meaning from what he says and the wider context in which it is uttered.

It can be seen from the partial analysis of extract 1 that one does not have to look very far in conversational data before one encounters examples of indirectness, inexplicitness and vagueness. In fact, conversations are seemingly awash with indirect, inexplicit and vague forms of language use. Nonetheless, while these terms are to be found elsewhere in the literature, it has been shown that they are not defined and used consistently in terms of their various manifestations. In what follows these terms will be delineated and exemplified with the aim of promoting greater clarity and, hopefully, further discussion.

Below a small selection of the HKCSE are analyzed in order to illustrate indirectness, inexplicitness and vagueness in discourse.

\section{Indirectness}

This study proposes a taxonomy for the notion of indirectness which consists of four paradigm cases: (1) conversational implicatures, (2) illocutionary acts, (3) indirect speech acts, and (4) pre-sequences. Conventional implicatures are excluded because these are not 
indirect in conveying meaning (see, for example, Mey 2001: 49-52; Zhang 1990).

\subsection{Conversational implicatures}

Thomas (1995: 119) defines indirectness as 'a mismatch between the expressed meaning and the implied meaning' and describes conversational implicature as 'one approach to explaining how people interpret indirectness' (see also Stenström 1994; Goatly 1995). Grice's (1975) notion of conversational implicature accounts for the ability of discourse participants to infer unstated or implied meaning from the expressed meaning. The speaker assumes that the hearer is able to infer the implicature intended from the context in which it is uttered. Grice (1975) puts forward the co-operative principle, consisting of four maxims, to account for the ways in which people generate and interpret conversational implicatures, and claims that his co-operative principle provides the means by which all human beings produce and interpret language. Within this framework, Grice describes a type of indirectness which results when the speaker blatantly flouts a maxim or maxim(s) and so generates a conversational implicature. In most talk, even when a speaker's expressed meaning does not seem to fully observe the maxims, the hearer assumes that the maxims are being observed at a deeper level, and so when a maxim is flouted, the hearer, through a process of inference, attempts to calculate the speaker's implied meaning. If participants in conversations did not view talk as essentially co-operative, it would not be possible to produce inferences. Grice describes flouting a maxim as a speaker exploiting the co-operative principle to produce a conversational implicature, or an indirect utterance.

Indirectness is widespread in oral communication even though, as Thomas (1995: 120-121) points out, it is both 'costly' and 'risky'. Being deliberately indirect is 'costly' in the sense that an indirect utterance takes longer for the speaker to produce and longer for the hearer to process (Dascal 1983), as psycholinguistic experiments have demonstrated additional mental work is required for both the speaker to generate an implicature and the hearer to produce an inference (Thomas 1995: 120). Indirectness is 'risky' in the sense that the hearer may fail to correctly infer the speaker's intended meaning. Another risk is that the hearer may deliberately choose to ignore the implied meaning and respond instead to the expressed meaning. Indirectness is a conversational strategy that is seen as intrinsic to conversational language use in particular, and therefore an integral part of every speaker's communicative competence (McQuiddy 1986).

Extract 2 shows a speaker producing a conversational implicature by flouting the maxim of quantity.

\section{Extract 2}

\section{a: female Hong Kong Chinese B: male British}

1 a: $\quad$ can I_'s mum come and help a bit (.) is she live nearby

2 B: she lives nearby but she's in her seventies now

2 a: oh

The participants are talking about speaker B's need of some domestic help. On line 1 
speaker a suggests that I_'s mum (speaker B's mother-in-law) could help assuming she lives in the neighbourhood. Speaker B, on line 2, confirms that distance is not a problem and then prefaces the information that she's in her seventies now with the use of but which has the conventional implicature (i.e. a non-context dependent use which is not a form of indirectness) of whatever comes next will not meet the expectations of what has gone before. Interestingly, speaker B does not provide the full information. By saying she's in her seventies now, he generates a conversational implicature that since I_'s mum is in her seventies, this inevitably excludes her from doing some of B's domestic chores. Speaker B has thus flouted Grice's maxim of quantity, and so the hearer must calculate what the 'missing' information is from what has been said and the full context in which it is said. Speaker a is then left to infer this implied meaning, which she does, and acknowledges it with an oh (line 3). This form of implicature should not be confused with ellipsis (discussed later as a form of inexplicitness) as ellipsis is not the complete absence of an entire proposition and its syntactic structure from an utterance. "Ellipsis is distinguished by the structure having a "missing' element" (McCarthy 1991: 43) but the proposition is retained in what remains of the structure.

\subsection{Illocutionary acts}

Indirectness is understood by Sew (1997: 358) as a style of formulating speech acts, and manifested as 'speech acts of indeterminate illocutionary points'. Austin (1962) proposes that when someone speaks, 'acts' are performed and that within an utterance a speaker usually performs three acts: The locutionary, illocutionary and perlocutionary acts. Austin states that the performance of a locutionary act (the formal literal meaning of the words uttered) is also to perform an illocutionary act (illocutionary force or pragmatic force). According to Leech (1980: 108), indirectness takes place whenever there is a disparity between sense and force.

Extract 3 illustrates an occurrence of indirectness as a result of a disparity between the locutionary and the illocutionary acts.

\section{Extract 3}

\section{B: male American b: male Hong Kong Chinese}

69. B: yea look up (.) the Chinese food is different too

70. b: do you like Chinese food

71. B: I tried er the Chinese food yesterday here it's delicious

On line 69 speaker B says the Chinese food is different too. The literal meaning (locutionary act) of this utterance is a statement by speaker B that the Chinese food in Hong Kong is also not the same as the Chinese food in the USA. The act performed in saying this utterance (illocutionary act) is to state that the Chinese food in Hong Kong is much better than the Chinese food in the USA (and this is revealed on line 71).

\subsection{Indirect speech acts}


Indirectness is also manifested in the form of indirect speech acts (Searle 1975). Searle (1975) introduces the distinction between direct and indirect speech acts. This distinction basically depends on the recognition of an utterance by the hearer on a particular occasion. English has one set of terms for sentence form and another set for utterance function. A direct speech act occurs when the sentence form and the utterance function have a direct relationship, for example, in the case of an imperative functioning to make a request or give an order. Indirectness in speech occurs when an indirect speech act is used, and that is, when the relationship between the structure of an utterance and its communicative function is indirect, for instance, when a declarative is used to ask a question.

Extract 4 illustrates the use of an indirect speech act. The participants were in a restaurant discussing preferences for food. Speaker $b$ has asked whether speaker B eats the innards of animal.

\section{Extract 4}

\section{B: male American}

1. B: do I eat meat

2. b: meat yea not inside body just like er brain er the the heart er

3. B: oh no I don't eat that //[ $\boldsymbol{\lambda}$ you eat that //

4. b: [((laugh))

5. b: yea because I'm Chinese sorry I'm Chinese I will eat this (.) all animals who is

6. the with four foot sounds good we'll eat just like dog er cat er

7. B: // $\pi$ you eat the $\operatorname{dog} / /$

8. b: no no no but

9. B: $\quad / / У$ you don't eat dog //

10. b: yea

Extract 4 shows three 'declarative-mood' questions performing interrogative functions (Brazil 1997: 99) (lines 3, 7 and 9) all uttered by speaker B. On line 3, speaker B asks whether speaker b would eat animals' 'brain' or 'heart'. B uses the same mismatch between sentence form and utterance function again on line 7 when he employs a 'declarative-mood' question to ask if speaker b eats the dog; and then another on line 9 to ask whether he does not eat dog. An analysis of intonation has shown that speaker B uses rising tone on lines 3 and 7 and falling tone on line 9. As stated by Brazil (1997: 101), a speaker makes intonation choices according to assumptions about the existing context of interaction. According to Brazil, rising tone is used by the speaker to request the hearer to confirm what he or she infers from the hearer's utterance is right, and falling tone is used when the speaker has made more than one inference from the hearer's utterance and asks the hearer to confirm that it was a particular inference, but not the other, that was right (Brazil 1997: 90-104). So, for instance, speaker B's 'you eat the dog' (line 7) said in rising tone is B asking b to confirm B's inference that b eats dog is right; whereas B's 'you don't eat dog' (line 9) said in falling tone means that in effect, B is asking b, 'Can I infer, or did you say (mean) this (i.e. you don't eat dog), or something else (i.e. you eat dog)? Please confirm that it was this (i.e. you don't eat dog).' Thus, while structurally similar, the choice of intonation adds different meanings to these examples of indirect speech acts. The 
intonation alone does not indicate to the hearer that a question has been asked by means of indirect speech acts. These examples also illustrate the claim that there is no one form of intonation that serves an interrogative function (see, for example, Brazil 1997), and this in turn supports the notion that negotiation of meaning in conversational interactions is context-dependent.

\subsection{Pre-sequences}

Pre-sequences are most typically found prior to making a request, invitation or announcement (see, for example, Mey 2001: 144-145; Miller 1994: 42-43; Yule 1996: 6769). According to Levinson (1983: 357), pre-sequences, such as pre-requests, are a form of indirect speaker behaviour which allows the speaker to avoid potential face loss by testing the waters before deciding on whether to perform the intended direct conversational actions. Pre-sequences comprise a closed set of speech acts and are often interpreted by the hearer as the projected speech act itself and they allow the hearer to give a 'go-ahead' response or a 'stop' response (Yule 1996: 67) before the anticipated speech act is actually performed.

Extract 5, which exemplifies a pre-sequence, took place in a Hong Kong dim sum restaurant.

\section{Extract 5}

\section{B: male British}

$\begin{array}{lll}1 & \text { B } & \text { [have you got a pen } \\ 2 & \text { a: } & \text { [have you got a pen (.) no I don't } \\ 3 & \text { B: } & \text { I've got a pen }\end{array}$

\section{a: female Hong Kong Chinese}

Customers in a dim sum restaurant usually need to use a pen to mark down on a card their choice of dim sum dishes. Extract 5 is interesting because both speakers B and a utter the same words, have you got a pen, at exactly the same time. The formal literal meaning of the two utterances is clearly identical but their functions as pre-sequences are quite different. Speaker B's pre-sequence prefaces an offer to lend his pen to speaker a and speaker a's pre-sequence is a lead-in prior to asking to borrow a pen from speaker B. Interestingly, both B and a correctly interpret the function of each other's utterance in the immediate context of interaction.

\section{Inexplicitness}

When distinguishing between indirectness and inexplicitness, this study goes some way to answering Bertucelli Papi's (1997: 23) questions: 'What are the limits of explicitness, up to what degree of explicitness are we authorized to develop a logical form, and what exactly are the boundaries which separate explicatures from implicatures?'. The present study considers 'implicatures' to be a form of indirectness, rather than inexplicitness. This study has chosen to use 'inexplicitness' rather than 'implicitness' because the latter term, which is typically contrasted with 'explicitness', is often used to describe forms of indirect 
language use such as indirect speech acts and conversational implicatures which are not considered to be realizations of inexplicitness. In this study, inexplicitness is used to encompass language forms which are non-specific when free of context, but which achieve specificity in the particular context in which they are spoken and heard.

Sinclair (1991: 497) claims that, in language use, when something is obvious, it is optional and 'the more obvious it is, the less likely it is to occur, and the more marked for meaning its occurrence'. Sinclair uses the term 'strict linguistic inference' to describe this phenomenon. Sinclair and Brazil (1982: 106-107) argue that there is an appropriate degree of explicitness in spoken discourse and note that over-explicitness can convey a patronizing tone. They offer the following example from their classroom data:

$1 \quad$ P: $\quad$ because I think water contains either oxygen or hydrogen

2 T: it contains oxygen and hydrogen

(Sinclair and Brazil 1982: 106)

In the above example, a teacher follows up an unacceptable response from a pupil, and in doing so, repeats the vocabulary used by the pupil. Sinclair and Brazil argue that this rarely happens in naturally-occurring conversation as it is usual to employ ellipsis and so avoid being overly explicit and patronizing. Classroom discourse is, of course, unusual in that the kind of evaluation employed by the teacher in the above example is commonplace in teacher talk, but it would be seen as socially unacceptable in conversations (Sinclair and Brazil 1982: 106). Such examples demonstrate the importance of being appropriately explicit, dependent on context of interaction, and indicate the relationship of an utterance to a particular discourse setting.

Scholars have described a range of linguistic manifestations encompassed by the notion of inexplicitness. McCarthy (1998: 39) explains the high number of deictic items and the resultant low number of full lexical words typically associated with conversations in terms of 'things do not need to be named'. Jucker and Smith (1996: 5) classify the ways in which discourse participants negotiate common ground as either implicit or explicit. Implicit negotiations of common ground are exemplified with personal pronouns, definite noun phrases and tag questions (Jucker and Smith 1996: 5). Comparisons across genres (Biber 1988; Biber and Finegan 1989) have also given rise to the use of scales to compare types of discourse in their use of elaborated (i.e. explicit) versus situation-dependent (i.e. not explicit) styles. The frequency of clausal ellipsis in conversations, compared to that of other discourse types, such as monologues, provides further evidence of this kind of genrebased language use (Ricento 1987: 751). For Placencia (1995:129), however, ellipsis, abbreviations and ambiguity are forms of realizations of indirectness, rather than inexplicitness.

In their study of intercultural English conversations, Cheng and Warren (1999b) have observed a high level of inexplicitness which in turn contributes to a lower level of lexical density since all of the linguistic realizations of inexplicitness have been found to consist of grammatical words (as opposed to lexical words) or, in the case of ellipsis, no words. For the conversational participants who are sharing and jointly constructing meaning in context, inexplicit language becomes specific; in other words, inexplicitness is not a product of a speaker seeking to be imprecise or ambiguous, rather it is a product of the speaker combining language and context to convey her or his meaning in an inexplicit form in the expectation that the hearer can assign an unambiguous meaning to 
it (Cheng and Warren 1999b). Paradigm cases for inexplicitness are (1) ellipsis, (2) substitution, and (3) deixis and reference (Cheng and Warren 1999b).

\subsection{Ellipsis}

Ellipsis is a form of inexplicitness which requires the hearer to interpret part of the discourse which the speaker has chosen 'to omit' from the context of interaction. There are three main types of ellipsis (Quirk et al. 1985: 861-2): Textual, situational and structural, based on the way in which the hearer interprets the meaning. Extract 6 illustrates situational ellipsis.

\section{Extract 6}

\section{B: male Australian}
1 B:
(is it) recording now
2 b: $\quad$ yes (it's recording because) that red light is on

b: male Hong Kong Chinese

In extract 6, for purposes of illustrating the notion of ellipsis, the words in brackets are put back to illustrate a hypothetical understanding of what speakers B and $b$ have chosen to 'omit' or have left unsaid. The items 'omitted' are typically personal subjects and main or auxiliary verbs. This type of ellipsis is classified as situational in that it requires the hearer to interpret the missing items from the immediate situation. In conversations, 'situational ellipsis', which is interpreted through the extra-linguistic situation, is the most common form of ellipsis (Carter and McCarthy 1997: 14-15; Cheng and Warren 1999b: 302). Speakers do not literally 'omit' words to be 'replaced' by the hearer but rather that when a conversation takes place, a different 'language game' (Wittgenstein 1953: 8-10) is taking place based on different rules, that is, with a different grammar of speech (Brazil 1995) and a higher level of inexplicitness. The real-time, linear production of spoken language gives rise to differences in the grammar compared to that of written language. Just one of the many differences that has been found is the much higher occurrence of certain forms of ellipsis (McCarthy 1998: 76).

\subsection{Substitution}

Substitution works by the speaker inserting a placeholding element (Halliday 1994: 370) to replace a lexical item(s). Like ellipsis, this form of inexplicitness is commonplace in conversations when a speaker assumes the meaning will be retrievable by the hearer. Indeed, it is argued (see, for example, Quirk et al. 1985: 860-864) that ellipsis and substitution promote both clarity and economy in discourse. Extract 7 shows how substitution works.

\section{Extract 7}

\section{B: male American a: female Hong Kong Chinese}

1 B: $\quad$ so do you go somewhere else for the weekend for a big meal family dinner 
2 a: I have already had one last Saturday er my mother (.) my parents-in-laws that

3 side

4 B: $\quad$ uh huh

The colleagues in extract 7 are discussing plans for the weekend. Speaker a says one on line 2 to substitute for a big meal family dinner uttered by speaker B on line 1 . It can be seen on line 4 that when speaker B produces $u h$ huh, he must rely on the preceding discourse in order to assign a specific meaning to this substitute item one.

\subsection{Deixis and reference}

Two other forms of inexplicitness are deixis and reference. The precise borderlines between these two forms and substitution and ellipsis are much discussed (see, for example, Brown and Yule 1983: 190-222) but will not be gone into here. However, the fine distinctions between all of the forms of inexplicitness are less important here than the way in which they all function by the speaker using a non-specific word, or no word at all, and the hearer then assigning a specific meaning in a particular context. Deixis covers expressions used by speakers to indicate person (e.g. I, we, him), time (now, tomorrow) and place (this, that, here) in a specific context (Levinson 1983). Specific meaning is achieved by the hearer understanding deixis in terms of the deictic centre (the speaker) and the temporal, spatial and personal relations relative to it at any particular point in the discourse. Reference is a form of cohesion (Halliday and Hasan 1976: 31-87) found in discourse and includes all referent items used to refer to specific referents (e.g. pronouns, articles and demonstratives). Hearers assign meaning for these reference items either textually (anaphoric and cataphoric references) or situationally (an exophoric reference). Cheng and Warren (1999b: 302) have found deixis and reference to be the most prevalent manifestations of inexplicitness in conversation.

Deixis and reference are exemplified in extract 8.

\section{Extract 8}

a: female Hong Kong Chinese

1 a: my uncle which uncle

2 B: the one we saw last night

3 a: $\quad$ last night that one (.) oh (.) first of all he er he's er an old communist

On line $1, m y$ is a person deictic expression and on line 2, last night is a time deictic expression. The use of the definite article (the) on line 2 is an example of anaphoric reference which refers back in the text to uncle. Two other examples of anaphoric reference are that and he on line 3 which also refer back to speaker a's uncle (one is an example of substitution).

The role of the context of interaction in meaning construction between speaker and hearer is clearly manifested in inexplicitness. The examples of substitution, and deixis and reference have illustrated that inexplicitness encompasses language forms which are nonspecific when free of context, but which achieve specificity in the particular context in 
which they are spoken and heard. Ellipsis, a different realization of inexplicitness, requires the hearer to interpret what the speaker has chosen to leave unsaid based on the context of interaction.

\section{Vagueness}

Crystal and Davy (1975: 112-114) discuss the tendency of speakers in conversations 'to avoid an excess of precision'. They identify types of lexical vagueness on a spectrum from items which express 'total vagueness', like thing and whatsit, to examples such as 'I've got some tomatoes, beans and things' and the use of the suffix -ish in colloquial English which are a mixture of precision and imprecision. Brown and Yule (1983: 8-9) also make the point that spoken language usually requires limited syntax (simple noun phrases and coordinating constructions) and contains a lot of 'general, non-specific' vocabulary, which is termed 'vagueness' in this study.

Much vague language occurs with numbers or quantities (Channell 1994: 18) to signal that they are to be interpreted as referring to a range rather than a specific quantity. Kennedy (1987) suggests that about $14 \%$ of all language is concerned with expressing quantity in some form, which makes this a very important area of language use. Sigurd (1988: 243) adds that the numbers used in approximative expressions are typically round numbers such as 10, 20, 50, 100 and so on.

Another large category of vague language use that has received attention is the use of vague lexical items or phrases, such as thing, that are often used instead of more precise items. Stubbs (1983: 23) describes the 'cavalier' way in which speakers in conversations supply information at times using words like thingummy and what-d'you-call-it, leaving the hearer to fill in the specific information.

Another kind of vagueness is scalar implicature (see, for example, Channell 1994: 95-100; Gadzar 1979; Levinson 1983: 134). Speakers select from a set, or scale, of items such as always, often, usually, sometimes, never which can be ranked in relation to one another. Often the scale has precise items at each end and vague items in between. The vague items are interpreted successfully by the hearer as long as there is a shared understanding with the speaker of the relative ranking of the items on the scale.

Carter and McCarthy (1997: 19) note that the use of 'vague expressions' is more prevalent in language use, especially in spoken discourse, than one might suppose. They note that in informal situations, it is deemed to be inappropriate to be precise as 'it can sound unduly authoritative and assertive'. They claim that speakers in informal contexts prefer to 'soften' the information they convey, and thus the use of vague expressions is a conscious choice on the part of the speaker and is not a product of 'careless thinking or sloppy expression'. An important point is made by Wierzbicka (1986: 612) that vague language is far from being meaningless simply because it is imprecise and that vague language does convey meanings which can be stated.

The category 'vagueness' covers a closed set of items which are inherently imprecise and which the participants interpret based on an understanding that the speaker is indicating, through the choice of vague language, that what is said is not to be interpreted precisely. Vague language consists of a closed set of identifiable lexical items that can be interpreted without recourse to judgements based on the particular context in which they occur. Given that the precise meaning can not be retrieved by the hearer, the successful use 
of vague language requires the participants in the discourse to have a shared understanding of the relative status of a particular set of vague lexical items. Based largely on the work of Channell (1994) and that of others (see, for example, Crystal and Davy 1975; Levinson 1983; Stubbs 1983; Kennedy 1987; Dubois 1987; Sigurd 1988), the three paradigm cases for vagueness proposed by the present study are: (1) vague additives to numbers, (2) vagueness by choice of vague words, and (3) vagueness by scalar implicature.

\subsection{Vague additives to numbers}

Vague additives are usually used with numerals (see extract 9) and consist of a word or phrase added to a precise figure to indicate the absence of precision (e.g. about, around, approximately).

\section{Extract 9}

\section{a: female Hong Kong Chinese}

\section{c: female Hong Kong Chinese}

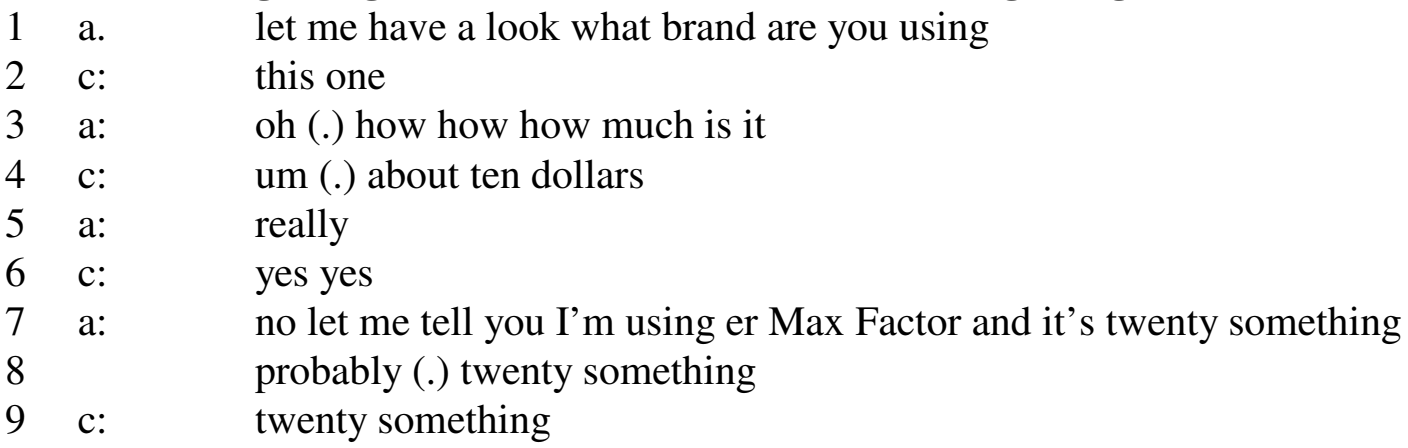

In extract 9, the speakers use two kinds of vague additives. On line 4 speaker c states the price as about ten dollars where the function of about is to indicate imprecision. Then on lines 7-9, both speakers use the vague additive something which denotes imprecision with regard to just how much more than 20 dollars the item actually costs. These instances of vague language also underline the inherent imprecision of these terms as the context makes them meaningful but does not make them fully precise.

\subsection{Vagueness by choice of vague words}

Extract 10 below illustrates vagueness by choice of vague words. The speakers are discussing the mainland Chinese they see in Hong Kong.

\section{Extract 10}

\section{B: male British}

b: male Hong Kong Chinese

1 B: and there seem to be an increasing number of mainland people here er 2 b: $\quad$ yes

3 B: $\quad$ I mean not not people who're obviously on business but I mean children and er 
$4 \quad$ like wives and (.) young young girls and things like that

On line 4, speaker B uses the vague phrase and things like that which is a fairly typical way to conclude the partial listing of items in conversations in which the expectation for precision is generally low (Channell 1994: 119).

\subsection{Vagueness by scalar implicature}

The last paradigm case for vagueness is exemplified in extract 11, where the speakers are discussing speaker A's attempts to learn Cantonese and both the speakers use vagueness by means of scalar implicature.

\section{Extract 11}

\section{a: female Hong Kong Chinese}

A: female British

1 a: did you did you make a little bit progress

2 A: $\quad$ I made some progress in the last ten years

On line 1 speaker a asks if speaker A has made a little bit of progress with the language and A responds on line 2 that she has made some progress. To interpret these examples of vague language, the participants need to have a common understanding of the relative status of these expressions. It can be seen that speaker A is effectively adjusting (upwards) the amount of progress that speaker a has suggested she might have made. This kind of adjustment suggests that discourse participants have a fairly keen sense of the meaning potential of such items.

\section{Conclusion}

This study hopes to contribute to the general field of pragmatics by delineating and describing taxonomies of indirectness, inexplicitness and vagueness in one paper, as well as describing their actual realizations with reference to a corpus of intercultural English conversations between Hong Kong Chinese and native speakers of English. The findings of the study also constitute a potential contribution to teaching the English language to learners as a second or foreign language so that English language learners become aware of these three forms of language use and become competent in processing these phenomena.

The study has examined indirectness, inexplicitness and vagueness in the genre of conversation. In conversation, meanings are both recognized and jointly constructed by both the speaker and the hearer, dependent on the context of situation (i.e. physical, social and linguistic contexts), as well as the meaning potential of what is spoken (Thomas 1995). Indirectness, inexplicitness and vagueness, while heavily context dependent, also contribute to the context in which they are spoken; and as a result, promote the construction and achievement of meaning between the participants. Through more clearly establishing the three main forms by which speakers most fully exploit context, and the ways in which each may be realized, this study hopes to have contributed to the discussion on how meaning is 
jointly constructed between conversational participants. First of all, indirect language use contributes to the ongoing context building as the conversation unfolds, and, through its contribution to the context, aids the hearer's inferencing. The speaker's meaning, 'concealed' at the literal level, is accessed by the hearer through the process of inferencing in which the full resources of both the language and the context are at the hearer's disposal. While speakers can not control the inferences produced by hearers, direct meanings are, nonetheless, produced from utterances that are literally indirect. In the case of inexplicitness, for instance, reference items such as it or this are inexplicit out of context but acquire a specific meaning within the particular context that is created when they are uttered. Such items acquire their specificity through a process of the joint construction by the participants of the specific context in which they are spoken. It is through this process that inexplicit forms lose their inexplicit status and achieve an explicit context-dependent meaning. Finally, vague language, on the other hand, retains its property of 'vagueness' and, while its vague meaning in a discourse is subject to the process of meaning construction by the participants based on the context in which it is said, it does not become precise rather than vague as a result of this process.

The fact that speakers so successfully employ indirectness, inexplicitness and vagueness is testimony to the very high level of interactivity that exists between the discourse participants, especially in conversations in which the responsibility for achieving meaning through construction is shared. This study lends further support to the view which sees communication as the progressive reduction of uncertainty (Brown 1989: 97-98), where speakers and hearers fill in the gaps in each other's knowledge, constructing meaning, and modifying their own knowledge representations as the discourse progresses (see, for example, Ellis 1985; Varonis and Gass 1985).

This study has examined intercultural English conversations that involve Hong Kong Chinese speakers of English. Further studies might examine spoken conversational English between native speakers of English and intercultural conversations that involve different groups of non-native speakers in order to compare the use of indirectness, inexplicitness and vagueness by different speakers.

\section{References}

Austin, J.L. (1962) How to do things with words. Oxford: Oxford University Press.

Bach, K. (1994) Conversational implicature. Mind and Language 9.2: 124-162.

Bertuccelli Papi, M. (1997) Implicitness. In J. Blommaert and C. Bulcaen (eds.), Handbook of Pragmatics 1997. Amsterdam/Philadelphia: John Benjamins, pp. 1-29.

Biber, D. (1988) Variation across speech and writing. Cambridge: Cambridge University Press.

Biber, D., and E. Finegan (1989) Drift and the evolution of English style: A history of three genres. Language 65.3: 487-517.

Brazil, D. (1995) A grammar of speech. Oxford: Oxford University Press.

Brazil, D. (1997) The communicative value of intonation in English. Cambridge: Cambridge University Press. 
Brown, G. (1989) Making sense: The interaction of linguistic expression and contextual information. Applied Linguistics 10.1: 97-108.

Brown, P., and S. Levinson (1987) Politeness: Some universals in language usage. Cambridge: Cambridge University Press.

Brown, G., and G. Yule (1983) Discourse analysis. Cambridge: Cambridge University Press.

Carter, R., and M. McCarthy (1994) Language as discourse: Perspectives for language teaching. London: Longman.

Carter, R., and M. McCarthy (1997) Exploring spoken discourse. Cambridge: Cambridge University Press.

Channell, J. (1994) Vague language. Oxford: Oxford University Press.

Cheng, W., and M. Warren (1999a) Facilitating a description of intercultural conversations: The Hong Kong Corpus of Conversational English. ICAME Journal 23: 5-20.

Cheng, W., and M. Warren (1999b) Inexplicitness: What is it and should we be teaching it? Applied Linguistics 20.3: 293-315.

Crystal, D., and D. Davy (1975) Advanced conversational English. London: Longman.

Dascal, M. (1983) Pragmatics and the philosophy of mind I: Thought in language. Amsterdam: John Benjamins.

Dines, E.R. (1980) Variation in discourse - "and stuff like that". Language in Society 9: 13-31.

Dubois, B.L. (1987) "Something in the order of around forty to forty-four": Imprecise numerical expressions in biomedical slide talks. Language in Society 16: 527-541.

Ellis, R. (1985) Teacher-pupil interaction in second language development. In S. Gass and C.G. Madden (eds.), Input in Second Language Acquisition. Rowley, Mass.: Newbury House, pp. 66-81.

Gadzar, G. (1979) Pragmatics: Implicature, presupposition and logical form. New York:Academic Press.

Goatly, A. (1995) Directness, indirectness and deference in the language of classroom management: Advice for teacher trainees? IRAL: International Review of Applied Linguistics in Language Teaching 33.3: 267-284.

Graddol, D. (1999) The decline of the native speaker. In D. Graddol and U.H. Meinhof (eds.), English in a Changing World. Aila Review 13: 57-68.

Graddol, D., and U.H. Meinhof (eds.) (1999) English in a Changing World. Aila Review 13.

Grice, H.P. (1975) Logic and Conversation. In P. Cole and J.L. Morgan (eds.), Syntax and Semantics III: Speech Acts. New York: Academic Press, pp. 44-58.

Halliday, M.A.K. (1994) An introduction to functional grammar. London: Edward Arnold.

Halliday, M.A.K., and R. Hasan (1976) Cohesion in English. Harlow: Longman.

He, Z.R. (2000) A further study of pragmatic vagueness. Journal of Foreign Languages 125.1: 7-13.

Hunston, S. (2002) Corpora in applied linguistics. Cambridge: Cambridge University Press. 
Jucker, A.H., and S. Smith (1996) Explicit and implicit ways of enhancing common ground in conversations. Journal of Pragmatics 6.1: 1-18.

Labrie, N., and C. Quell (1997) Your language, my language or English? The potential language choice in communication among nationals of the European Union. World Englishes 16: 3-26.

Kempson, R. (1977) Semantic theory. Cambridge: Cambridge University Press.

Kennedy, G. (1987) Quantification and the use of English: A case study of one aspect of the learner's task. Applied Linguistics 8.3: 264-286.

Leech, G. (1980) Principles of pragmatics. Harlow: Longman.

Levinson, S. (1983) Pragmatics. Cambridge: Cambridge University Press.

Mazzie, C.A. (1987) An experimental investigation of the determinants of implicitness in spoken and written discourse. Discourse Processes 10: 31-42.

McCarthy, M. (1998) Spoken language and applied linguistics. Cambridge: Cambridge University Press.

McQuiddy, I. (1986) Some conventional aspects of indirectness in conversation. Ph.D. dissertation, The University of Texas, Austin.

Mey, J. (2001) Pragmatics: An introduction. Oxford: Blackwell.

Miller, L. (1994) Japanese and American indirectness. Journal of Asian Pacific Communication 5.1\&2: 3755 .

Placencia, M.E. (1995) Explicitness and ellipsis as features of conversational style in British English and Ecuadorian Spanish. IRAL 33.2: 129-141.

Quirk R., S. Greenbaum, G. Leech, and J. Svartvik (1985) A comprehensive grammar of the English language. Harlow: Longman.

Ricento, T. (1987) Clausal ellipsis in multi-party conversation in English. Journal of Pragmatics 11:751-775.

Riley, K. (1988) Conversational implicature and unstated meaning in professional communication. The Technical Writing Teacher XV.2: 94-104.

Searle, J.R. (1975) Indirect speech acts. In P. Cole and J.L. Morgan (eds.), Syntax and Semantics Vol. 3: Speech Acts. New York: Academic Press, pp. 59-82.

Sew, J.W. (1997) Power pragmatics in Asian languages. Language Sciences 19.4: 357- 367.

Sigurd, B. (1988) Round numbers. Language in Society 17: 243-252.

Sinclair, J. McH. (1991) Shared knowledge. Georgetown University Round Table on Languages and Linguistics 1991. In J.E. Alatis (ed.), Linguistics and language pedagogy: State of the art. Washington D.C.: Georgetown University Press, pp. 489-500.

Sinclair, J., and D. Brazil (1982) Teacher talk. Oxford: Oxford University Press.

Sperber, D., and D. Wilson. (1986) Relevance: Communication and cognition. Cambridge, MA: Harvard University Press [2 ${ }^{\text {nd }}$ edn 1995]. 
Stenström, A-B. (1994) An introduction to spoken interaction. London: Longman.

Stubbs, M. (1983) Discourse analysis: The sociolinguistic analysis of natural language. Oxford: Basil Blackwell.

Stubbs, M. (1996) Text and corpus analysis. Computer-assisted studies of language and culture. Oxford: Basil Blackwell.

Thomas, J. (1995) Meaning in interaction. London: Longman.

van Dijk, T.A. (1979) Pragmatic connectives. Journal of Pragmatics 3.5: 447-457.

Varonis, E.M., and S.M. Gass (1985) Non-native/non-native conversations: A model for negotiation of meaning. Applied Linguistics 6.1: 71-90.

Wierzbicka, A. (1986) Precision in vagueness: The semantics of English 'approximatives'. Journal of Pragmatics 10: 597-613.

Wittgenstein, L. (1953) Philosophical Investigations. Oxford: Blackwell.

Yule, G. (1996) Pragmatics. Oxford: Oxford University Press.

Zhang, J.Z. (1990) Ranking of indirectness in professional writing. Journal of Technical Writing and Communication 20.3: 291-305. 